\title{
Children's narratives of post-divorce family life: from individual experience to an ethical disposition
}

\section{Carol Smart}

\begin{abstract}
This article draws on interviews with 60 children and young people to explore how they construct narrative accounts of post-divorce family life. Rather than seeking to describe children's experiences as if their accounts are simple factual recollections, the focus of the article is on how young people position themselves in their narratives and the ways in which they construct their past experiences. It is argued that these narratives are multi-layered, often revealing ambivalence and contradictions. The conclusion turns to the question of whether these individual accounts can give rise to what might be referred to as an ethical disposition in which children's experiences can inform a broader social ethos on how to divorce 'in the proper manner'.
\end{abstract}

\section{Introduction}

Children, especially young children, are not expected to have well formulated or highly practiced narratives about their family lives. I do not mean by this that they are not expected speak about their parents and sibling, but rather that they are thought unlikely to have coherent, linear stories to tell about their family history, adult and kin relationships and why their families are organised in the way that they are. One reason for this may be that we do not encourage children to speak about the quality or shape of family relationships in 'public' because the family is still a private matter. Rarely are children asked in a sustained way how they relate to their mothers or fathers unless they are in therapy, 'at risk', or part of a research project ${ }^{1}$ (eg Morrow, 1998; Dunn, 2003; Harold et al., 1997), and it is possibly even more unusual in everyday contexts for children to be asked, outside the family, what they think about their parents' conduct - except perhaps by members of friendship groups. ${ }^{2}$

Yet it may be the case that being able to provide a narrative account is indicative of being able to be reflexive about one's situation (Thomson et al., 2002). It may be that 'objectifying' one's life through narrative allows one to stand outside oneself and evaluate experiences and events, rather than just 
experiencing them in a fatalistic, reactive way. Constructing a narrative may also be part of a process of making sense of past experiences, of linking events, and seeing patterns. This may enable the subject and author of the narrative to be more prepared for future events, to evaluate other people's accounts, and to have a greater sense of control over their lives (Gergen and Davis, 1983). It may also allow them to draw 'lessons' from their experience which can be generalised and utilised as a means of guiding future behaviour (Duncombe and Marsden, 2003). Thomson et al., go slightly further and quote Bruner (1987) to suggest that narratives are not simply self reflexive interactive stories but that they may become ways of structuring future experience.

Ways of telling and ways of conceptualizing that go with them become so habitual that they finally become recipes for structuring experience itself, for laying down routes into memory, for not only guiding the life narrative up to the present but directing it into the future. (Bruner in Thomson et al., 2002: 339)

Narratives are therefore not necessarily just 'accounts', they may become part of the lens through which we interpret events as well as becoming part of the structuring of future events. This means that narratives are significant because they have the potential to weave perceptions of the past into future scenarios and experiences.

In this paper I shall explore children's narratives of post-divorce family life in order to show how children may be positioning themselves in relation to this form of family change. Typically children are depicted as the victims of divorce (eg Amato and Booth, 1997; Cockett and Trip, 1994) and while there is substance to this claim, the more children themselves are invited to talk about how they perceive and experience divorce, the more it is possible to detect alternative positions that children themselves may actively adopt (rather than being passively ascribed to by others) (Morrow, 1999). What is more, the divorce of one's parents can be rightly described as a 'critical moment' (Thomson et al., 2002) and so has the character of being a life changing event. This means that children are likely to have much to say about how their family lives have been changed or affected. The divorce may therefore trigger narratives in children in the way that routine everyday life does not. Previous studies we have carried out have established that children have a lot to say about how their lives change on divorce (Smart et al., 2001; see also Butler et al., 2003) but we have not given consideration to the nature of the narratives the children have offered. We have treated interview data as simple statements of past experience, rather than as 'stories' which may take different shapes and forms and which may position the speaker in different ways according to how they chose to tell the story. So here my first aim is to identify the types of accounts that children offer and to try to relate these to how reflexive the children appear to be and the degree of distance they can achieve between what they construct as their own lives, and the emotional milieu that 
is their parents' lives. My second aim is to consider the extent to which children may be able to generalise from their specific context in order to develop broader ethical evaluations of family life.

\section{A note on the sample}

The sixty young people in this study had all experienced their parents' divorce and had lived post-divorce family life for at least 5 years and often as long as 12 or 15 years. All of them had been recruited to participate in previous studies carried out at the Centre for Research on Family, Kinship and Childhood at the University of Leeds. One of these studies was on children's experiences of shared residence after divorce and formed part of the ESRC's programme on Childhood 5-16. In that study we interviewed 65 children from 47 families. The other was a follow up study of the children of a sample of parents whom we had previously recruited into a study on how parents negotiate over residence and contact on divorce or separation (Smart and Neale, 1999). There were 52 children from 32 families in this study. The results of these two studies were fully reported in Smart et al. (2001). Having completed these two studies it was decided that it would be worthwhile to track a subset of the original 117 children to see how their experiences of post-divorce family life were developing and changing. Thus all the young people in the follow up study discussed here have been interviewed twice, with a gap of approximately four years between the interviews ${ }^{3}$. It was our aim to re-interview half of our original joint sample and we were successful in reaching slightly more than this (60 out of 117). The strategy we used to select the subsample was designed to recruit equal numbers of boys and girls and to ensure that we included children who came from the full range of socio-economic backgrounds. Thus some came from privileged middle class backgrounds, others from much more deprived backgrounds living with lone mothers. In the first round of interviews the age range of the largest segment of our sample was 8-11 years. This meant that the second time round the largest group was aged between 11 and 15 years. All were ethnically white and lived in the North of England in predominantly urban settings (cities or market towns). The sample reflected a range of residence and contact arrangements, from children who had ceased to have any contact with the non-residential parent (in our subsample these were all fathers) to children who moved between two homes regularly. Some children had parents who were still enmeshed in conflict, for others the conflict had abated, and for others there was relative harmony.

\section{Producing narratives}

In the process of interviewing the young people in our study it became clear that they were weaving together a number of different elements of their lives 
into an intricate, and sometimes contradictory, pattern. Mason (2004) speaks of 'interwoven layers' in relation to the narratives that her interviewees provided and this term captures the nature of most of the accounts we were given. The interwoven elements included:

1. Their own emotions and feelings (past and present)

2. The emotions and feelings of other family members (past and present)

3. Actual events

4. Clear and less clear recollections

5. Gaps in knowledge and understanding

6. Current uncertainties

7. Future hopes and expectations

While some children reported on these matters as discrete issues, others were able to weave them into narratives of explanation, cause and effect. Moreover it was rare for there to be just one story; often several overlapped and there were also contradictory emotions and recollections embedded in the accounts. Different children constructed narratives with different degrees of sophistication and complexity but this did not seem to be simply a function of age. But age did relate to the extensiveness of a child's experiences and as the children grew older they came to 'know' more about the past as they asked their parents more questions, or as parents and other relatives became more willing to fill in gaps or offer their own accounts of past events. So older children often knew more or could offer more extensive explanations.

It is, of course, important to acknowledge the role of the interviewer in the production of narratives. Indeed, it might be better to speak of co-production since our questions and vignettes 'encouraged' the children to produce accounts (Mann, 1998; ${ }^{4}$ Lupton and Barclay, 1997: 93-4; Holstein and Gubrium, 1994). The interview is an 'unnatural technology' (Rose, 1966: 180) no matter how conversational it may become. The purpose of the interview is to elicit speech about a given topic or topics and it would be disingenuous to present the narratives of children as if they were somehow spontaneous events. This 'unnatural technology' also may have produced a degree of reflexiveness in the children that might not otherwise have occurred, or might have occurred later. Some, for example, volunteered that the first interview (in the previous study) had made them think about things in a way that they had never done before. Moreover, the interview process may have had the effect of 'sociologising' their understanding of their circumstances. By this I mean that the children recognised themselves as being of interest to research and thus part of a category of 'special' children. This meant that for many they could see divorce and family transition as a social phenomenon, and not just a personal tragedy affecting their particular family in isolation.

The 'co-production' of these narratives had at least one further implication. The children tended to tell their stories as if they were finished. This is, perhaps, inevitable given that this reflects the imperative of the interview. But it is important to avoid taking this sense that their circumstances had reached a 
final stage into the analysis of their narratives. Because the children speak as if they have reached an end point, it does not mean that the reader should take this literally and imagine that nothing more will change or happen in the lives of these children. And the children themselves did speak of their futures and acknowledged that there will be further changes, even if these were related to growing up, more than to further changes in their parents' circumstances.

\section{The children's narratives}

In analysing the accounts we received there appeared to be two broad conceptual ways of grouping the stories. The first conceptual axis was an organising principle which was 'imposed' on the stories and which involved grouping them according to the different shape or structure that their families took after divorce. The second axis arose from the emotional content of the stories that the young people told, with some telling stories which spoke of achieving emotional contentment, and others speaking of on-going emotional turmoil and distress. It is, perhaps, important to say something about how I arrived at these two axes for my analysis.

The issue of family structure after divorce has been identified as particularly significant for children's wellbeing. Thus living with a lone mother is identified with a drop in living standards (Maclean, 1991), while multiple changes and/or the introduction of multiple step-partners has been associated with emotional distress (Flowerdew and Neale, 2003; Dunne, 2003). On a more optimistic note, authors like Stacey (1996) have referred to the divorce extended family, whereby children gain more adults and other children in their lives, and this is associated with expanding resources and horizons. So these structures form a potentially important context to the stories the children were constructing. These structures can be described as ranging from 'uncomplicated to 'complicated', with the former representing situations where parents have divorced and one has repartnered. In this context the child has to make a major adjustment to the divorce, and then often to having one parent repartner and the introduction of step-sibling, but has not had to face further significant changes. Complicated structures represent those where both parents may repartner, where several further children are introduced through the new partnership or are born to the new union, and where there may be several new partners and an ebb and flow of step-sibling. This complicated structure does not have to mean chaotic, however. The divorce extended family, where children live with both parents half the time; have sibling, half sibling and step sibling; and where they accrue multiple sets of grandparents, can be both ordered and stable. But nonetheless, the children have to learn to accommodate to many more people and relatives in their lives after the divorce.

The issue of the emotional content of the children's narratives is more complex. Clearly the sorts of stories they told were likely to be full of both emotions (in the present act of telling) and accounts of emotions (recalled 
from the past). Thus it appeared that some children could speak fairly happily about a time when they were very unhappy, thus giving the impression that it was a phase in their lives from which they have recovered or moved on. Yet others spoke angrily or unhappily about past events which had been unhappy, and also expressed ongoing discontentment. For yet others, they reflected that they had been quite content (at the time of the first interview) but that things had deteriorated for them and they had become unhappy or angry by the time of the second interview. Thus there were complex, dynamic and multi-layered expressions of emotion and these could shift in the course of an interview as certain events, perhaps forgotten, were recalled.

My attempt to group the narratives of these young people along these two axes of structure and emotion should therefore be treated only as a device to help to see some of the features of, and differences between, the accounts. These structures and emotions are potentially subject to considerable change, and so ultimately should not be treated as static or fixed. I shall explore each of these narrative accounts in turn.

\section{Uncomplicated structures and contented accounts}

In this kind of narrative the children suggested that they were aware that their parents were not getting on but, even so, they rarely expected that they would separate. One parent may have become involved with another person, but if so, the children were often unaware until later. What the children's accounts outlined were typically periods of considerable uncertainty, especially if the departure of one parent was associated with moving home and a sudden drop in living standards. They may have been aware of an ongoing strained atmosphere between their parents, or even rows and distress which continued for some time. But they then recalled a process of settling down, with their lives taking on a new shape, and where 'new' adults and step or half siblings might have been added such that their family gradually expanded. For these children and young people the divorce of their parents had become unremarkable, something that had happened in the past but to which they had all become accustomed.

Jamie (13): Yes it's fine now. I am glad we moved. I think being closer to my Dad [is great] and now I have got some more friends and stuff it's fine. And everyone is happy here so that makes us feel a bit better in general. It makes a difference ... knowing that we can go there whenever we want really. Before we couldn't just, we could say 'Can we go down?' but we had to organise it. Now I can just ring him and he can just pick us up if he isn't doing anything. Erm, sometimes it's weekends in a row, sometimes we miss a few weeks. It's just whenever we feel like it.

Jamie and his brother Matthew lived with their mother and her second husband and together they had a daughter who was simply regarded by the 
boys as their sister - there was no concept of 'half' sister in their vocabulary. They has been very involved with her, and also got on very well with their 'step' dad, although they did not use the terminology of 'step' parent either. It was made much easier by the fact that their biological father and their 'step' father got on well. Their biological father had had a few girlfriends and this had caused some tension, but this was seen as a distant issue because he had not re-married.

Jamie (13): I can remember sometimes that I wanted them to get back together, but now I don't want them to get back together in a way because, erm, we are settled and we have got a new family and stuff.

Matthew (12): Oh well, I wanted them back together, but it's fine now. I'm OK about it now. Well 'cause, like, I'm older and I understand it better so...

Their story, at this point, was one of gradual improvement giving rise to a sense of well-being, trust and contentment.

\section{Complicated structures and contented accounts}

As noted above the children providing these kinds of narratives were weaving more relationships into their accounts. Thus parents may have re-partnered, had further children and then separated, then possibly partnered again. Or they may have repartnered with people who had children from previous relationships, who were in turn moving back and forth between parents. The young people had access to many adults and new siblings, and often accreted new grandparents too.

Ruth: Well there's a bit of an [issue there]. Because her [mother's former partner] family are working class. They are a bit ... they ... it took them a while for them to understand that she was a lesbian and Magda got very upset when my Granddad died on Magda's side and they said I couldn't go to the funeral.

Interviewer: Right. You mean Magda's Dad?

Ruth: Oh no sorry my Great Granddad. It was Magda's Granddad.

Int: But you called him your Granddad?

Ruth: Yep.

Ruth had three parents, her biological mother, her other mother who she just called Magda, and her biological father. She spent time each week with all of them. They had all re-partnered and her father's partner had two children and was planning to move in with him. Ruth's narrative included all of these 
people, each of whom had something different to offer her. The only people who were at all problematic for her were Magda's parents: otherwise she expressed complete contentment with her situation.

Ruth: Well it was a couple of years ago they said something [about me moving around between homes so much] and at the time I thought, 'Well yes it isn't brilliant' but now I think I quite like my life like it is. You know I have got three lovely parents, three whole sort of like new different lives, do you know what I mean?

Ruth's narrative focused on the quality of her relationships and although she spoke of unhappy times, she did not identify the structure of her family as part of the problem, even though it was complex by many children's standards.

Other children's stories could be complex in slightly different ways, but their stories still retained a core ingredient about having lots of people around who were positive resources for them in their lives. For example, in Holly's story much of her account focused on her abundance of siblings. She lived half her time with each parent; and in her mother's house she lived with her Mum and Clive [mother's partner] and their daughter Katie. In addition there was Olivia who was Clive's daughter from a previous relationship. Her father, who she lived with half the time, also had a son by another relationship. This half brother lived with his mother some distance away, so she saw him less often, but she still spoke of him as her brother. Holly's experience, as she recounted it, was that her extended family was just spread across a number of households and that, as time had passed, she had been fortunate to gain more sisters. In her story she was both an only child, and also a child with many siblings; she had several parents and could draw upon a rich range of interpersonal resources. Her story was one of expanding horizons in which she did not present herself as burdened by past problems. She did anticipate possibly future changes with some anxiety (because her father was about to start living with someone) but her narrative construction of herself was a long way away from being a victim of divorce.

\section{Uncomplicated structures and unhappy accounts}

The accounts described above give the impression of the children being able to stand back from the epiphanal experience of the divorce, to depict it as hard - even traumatic - but they are able to position themselves as coping and as survivors whose lives may be different but who are contented, even happy, with the outcome. But a different group of children constructed narratives which were much closer to the adult 'victim' narratives that might be provided by the 'injured' party to a divorce (Day Sclater, 1999). Take, for example the case of Jason (aged 17) and Josh (aged 14) whose father left their mother 11 years previously and very soon after established a new household 
with the woman he had had an affair with. They reported that they did not see their father very often, partly because he lived quite a long way away, but mainly because they refused to go to his home because it meant being with his new wife.

Jason (14): No I don't like her [father's wife].

Interviewer: So she's not an important figure in your life?

Jason: No.

Int: Can you say a bit more about why you don't like her, what it is?

Jason: 'Cause I just don't want to get on with her.

Int: You don't want to get on with her?

Jason: No. . . I know that I'm being quite shallow but ...

Int: Would you say that relationship has always been the same between her and you?

Jason: Yeah, she's very nice like when she speaks to me and stuff but I just...

It is significant that Jason's story trails off and in this way he gives the impression that his dislike of the new wife is ambivalent and complicated. Josh, his older brother, was equally ambivalent and offered two contradictory accounts of his parents' divorce. In one, which was much less sustained, he recalled that his parents' marriage was going wrong for some time anyway, but in the other he blamed his father's new wife for all the troubles his family endured. His main interpretation of the situation was, however, to be found in the context of an extremely powerful 'blame' narrative which was also constantly rehearsed and refreshed by his extended family and grandparents.

Josh (17): His mum and dad, we always talk about it, me and them two, we talk about how much we all hate her. And they know him well, obviously, he's their son, and they still say, they would never say it to his face because they know it would break his heart, but they still don't know what he is doing with her because, they just can't see it in her, they just can't see what [he sees in her]....

Int: Is it that you don't like her as a person, if you met her outside that situation would you still not?

Josh: I still wouldn't like her. It's like, if she was a nice person genuinely, then of course I can't deny that I like her. But I still won't 'like her' because of what she has done. But I mean, from what I believe, I don't know, I was young at the time, I think my Mum and Dad weren't having the best time 
anyway, being married, and then she sort of like finished it all off which I mean...

Josh: I don't, like, call her my step mum or anything. I get pissed off when people do call her that, and mum winds me up about it like, 'How's your step mum?' or whatever.

Jason and Josh therefore tended towards providing a 'blame' narrative with simple 'rights' and 'wrongs'. The problem was that cutting across this narrative was a strong sub-theme of how much they missed their father, and how much they wanted to be with him doing 'proper' things and spending real time together. This was offered in a much less abrasive tone and in a more halting fashion. Their public narrative was a straightforward moral tale in which their father had made his bed and so must lie in it; but their emotional narratives were much more ambivalent. Both of these young men saw their lives, and the life of their mother, as ruined by 'the other woman'.

It was interesting, however, that in some cases we found that while one sibling would provide an emotionally contented story, his or her brother or sister might construct a much more troubled story composed of very different negative emotions and conclusions (see also Dunn, 2003; Sheehan et al., 2004). The accounts by the sisters Naomi (aged 13) and Leonie (aged 16) are an example of this phenomenon. Both sisters were aware that their parents' marriage ended eleven years previously when their father told them that he was gay. They had a 50:50 shared residence arrangement and both sisters discussed openly the animosity between their parents and reported that they had had to carry messages back and forth. Naomi reported that she got on well with both her mother and her father and their respective partners. Her account of her parents' relationship was that she wished they would 'grow up'. She had become more philosophical about her family as she began to realise that, although it was unconventional, that it could have been much worse. She was clear that both her parents had always supported her in what she wanted to do and she reported that she had come to realise that friends who she imagined had perfect families had even worse troubles.

Naomi (13): Yeah about a year ago I think. And so I accepted that [I have a fine life] and then I thought, well I quite like Ian [mother's partner] and I like, I quite like Steve [father's partner] and I'm happy with the way things are. And I suppose if I just, I think I've been selfish to want people to be unhappy just so it can be like, look like a perfect family [to] everybody who looks on, but when really there is no perfect family.

Leonie's account was different, however, and she positioned herself as still caught between her parents. Her account had it that her mother put more pressure on her than she did on her sister and that this was because she resembled her father. The more Leonie felt she leant towards her father, the more she felt that her mother pressured her into spending time with her. Although 
it was apparent that they both fully understood that their father was much better off financially compared with their mother, especially since his partner moved in with him, this had different meanings for each of the sisters (Parkinson et al., 2005). For Naomi it was just a fact of life, but for Leonie it was experienced as an opportunity for her mother to manipulate her. Her account was structured around her interpretation of her mother's bitterness.

Leonie (16): Well it's just annoying, I mean it's also just the point that it happened 11 years ago. They weren't, they've been apart more time than they'd been together. And before she always used to use the line, 'Oh you know I'm a single mother you know, I'm struggling on my own with kids blah, blah, blah'. And now she hasn't got that excuse because she's got a partner (laugh). Now it's just 'Oh you don't care about me' - major guilt trip, that type of thing (laugh).

In Naomi's account she seemed able to distance herself from the emotional turbulence of her parents' separation, while in Leonie's account she depicted herself as engaged in a struggle against her mother's interpretation of events. Naomi stands back from 'her life' and reflects upon it, while Leonie appears as if she is carried along by life, unwillingly experiencing quite volatile emotions.

\section{Complicated structures and unhappy accounts}

Children who spoke of their experiences in this way often provided an account where the divorce of their parents had been significant, but where this event had been superseded by larger events that followed. This meant that the divorce in itself occupied less space in the narratives as it gave way to more recent issues and troubles. The narratives unfolded a complex kaleidoscope of events, emotions and relationships which compounded together to create troubling stories in which the young people were enmeshed (Flowerdew and Neale, 2003; Moxnes, 2003). The issues recalled included such problems as alcoholism, depression, eating disorders, disability, and major health problems. In addition there was often a theme of interpersonal problems such as unpopular 'step' parents, a succession of 'step' parents, a dislike of sibling or step-sibling, an ongoing hostility between parents, arguments over money, and finally over-controlling and/or manipulative parents.

Angela (20): You know all parents mess up their children whether they intend to or not. And then I have talked to my friends and they say 'Actually no'. Some people have normal parents and it doesn't happen like that and they are just there to support them when they need it. And I'm like, 'Well I never had that experience you know'. The friends that I had, their lives were interesting and colourful too.... I think all parents do pass on neurosis to their children even the, even the normal ones. So I think possibly I might be more a product of the way my actual parents are than because they are divorced. 
A key element of these narratives was that the starting point for all of them was the intense hostility between parents before, during and after the divorce. This was the context within which other major life events arose. These stories revealed that children felt they could not confide in a mother about (for example) a step-mother as this merely fuelled the hostility; nor could they talk to a father about their concerns over (for example) their mother's drinking or depression because they knew this would aggravate matters. This means the children often felt very isolated, lonely and depressed.

Megan (14): Yeah. But at the time when it was happening I was really quite depressed. So I wouldn't be able to talk about it without bursting into tears type of thing. ... No, I cry too much anyway so [laughing]. Back then I wouldn't have been able to have talked about it at all. But now I'm ok with it like almost completely.

From the accounts of these narrators it would seem that where there was parental hostility their choices were either to side with one parent (as with Jason and Josh above) or to become very isolated with the feeling that they were quite without adult support as they navigated their own problems with growing up or the additional ones caused by their parents' behaviour. This is captured in the following account:

Caitlin (16): I think it's very important [parents talking to each other] because, if your parents were like constantly arguing with each other or about each other, you'd feel more like your family had gone. Where as if they are still talking then it's more, you know your family is still there even if they are not together.

These accounts depict these young people as caught between parents, but there was also an emergent 'blame' narrative as they increasingly saw their parents as responsible for making their lives particularly hard (Duncombe and Marsden, 2003). However, equally significant was the theme of being alone and being lonely through which these young people constructed themselves as abandoned by adults.

It was with this group of children that we found some who were not either willing or able to provide full accounts of their family relationships. When asked to explain or elaborate on events or feelings they would tend to assert only that they were 'not bothered' (that they did not see their father for example) or they would give very brief answers, whereas elsewhere they might be more fulsome. Like Brannen et al. (2000) who had similar experiences, we did not press these young people to say more than they were comfortable with. But their fragmented stories gave the impression that their emotional experiences were still too immediate and raw for them to be able to stand back and reflect upon them, or upon recent events. 


\section{Conclusion}

The ways that these young people constructed their narratives of post-divorce family life included stories of coping, surviving and even personal growth at one end of the spectrum, through to stories of blame, victimisation, loneliness and even unspeakable pain, confusion and withdrawal. However, as I argued at the start, narratives should be seen as more than mere stories or factual accounts of past events or feelings. In line with Thomson et al. (2002) and others, I have argued that ways of conceptualising are part of the tools with which experiences are recalled and also shaped. The young person whose story is one of coping, and who recalls events and moments when he or she successfully managed adversity, is building a past which helps to shape the kind of person they believe themselves to be. This may, in turn, help to shape how they deal with future adversity and problems. On the other hand, the young person who feels their parents are to blame for all their troubles (whether this is objectively true or not) may construct their broader experiences in terms of being victimised or abandoned.

There is yet another way in which we can suggest that individual, personal narratives have broader social implications than might be immediately apparent. This is in the process whereby the individual moves from an account of their personal experience, to shaping an ethical disposition to guide their own actions; and even to go beyond this to contribute to a more generalised moral sensibility (Sayer, 2005). The process of divorce through which all these children had lived provided them with a kind of spectacle through which they could observe their parents behaving well or badly (and many shades of grey in between). Because divorce shatters the taken-for-grantedness of family life for many children, and because it allows children to witness their parents' emotions and pain in a new way, they can engage in their own evaluation of how they behave. This allows for the development of a generalised moral ethos to emerge from concrete, personal experiences. The account by Cheryl below reveals the iterative process between personal experience, feelings, recognition of the problem, and an emergent ethical disposition:

Cheryl (12): If you are worried about what the children want, the children don't want you to [argue]. Because when my parents ... I can remember some arguments and I can remember thinking 'Oh my god my parents hate each other' but now I don't think they hate each other; they are friends. But if you argue in front of your children they will think you hate each other. You need to split up or at least give yourselves some space until you've thought about it because that is what is best for them. They need to know that you're not behaving like a couple of school kids; they need to know that you are handling it and that you don't want to have to turn [to] them. Because if you have an argument and you are in the same house who else have you got to go to? Your kids have got to put up with that. But if 
you are not in the same house then you are free. Talk to them about it but the best thing is to split up.... Only argue when you are together. Don't argue over the phone or anything like that.

Many of the children we interviewed had well developed ethical dispositions on how adults should treat one another, and in particular how they should behave towards their children. What many of them appeared to share ${ }^{5}$ was that there was a need for parents to learn how to divorce in the proper manner'. As it was too late for these particular children's parents to learn this (with the exceptions of those who were deemed to have done it well anyway) the children were thinking of the future behaviour, and of the futures of other children (perhaps even their own). They were generalising from their experiences and weaving their own accounts into potentially, socially relevant ethical dispositions.

The responses of the young people in the study implied that they had a vision of what a proper childhood should be and what the proper responsibilities of parents were. These things were seen as foundations to a particular quality of life, which they thought that children were entitled to expect. The children whose parents rowed and gave vent to their anger and bitterness were seen as robbing their children of both emotional and tangible assets. These narrators expressed the feeling that their parents damaged their lives, not by divorcing, but by failing to divorce in the proper manner. They articulated a loss and impoverishment which was not just economic but relational, and many saw this as an avoidable detriment. I have suggested that these narratives signify the potential emergence of a social ethic, rather than just the iteration of a personal biography or experiences. But they also indicate that there are a wide variety of subject positions that children can adopt when faced with their parents' divorce and that it is sociologically valuable to capture the complexity of their multi-layered accounts.

University of Manchester

Received 4 October 2004 Finally accepted 17 June 2005

\section{Acknowledgements}

I would like to thank The Institute of Advanced Study at the University of La Trobe where I was Distinguished Visiting Fellow in March and April 2004 for allowing me the space and time to work on this paper. I would also like to thank members of the Law Faculty at the University of Melbourne for their helpful comments on the first draft of this paper. Naturally most important of all are Dr Bren Neale and Dr Jennifer Flowerdew with whom I have worked on this project.

\section{Notes}

1 For most of the young people in our study, the first opportunity they had to reflect and construct narrative accounts of their varied and sometimes complex experiences of family change was when they were asked to do so for our research project. 
2 I accept of course that children will 'talk' about their families and may even compare notes and list complaints to their friends. But this talk is not the same thing as constructing a narrative account of family life. Butler et al. (2003) point out that the children they interviewed were, in the main, willing only to 'confide' personal issues about divorce to their best friends. This suggests that the more sensitive the issues, the less public the stories will be.

3 The follow up interviews with 60 of the original 117 children were conducted as part of the Enduring Families? project (ESRC Ref R000239248) with Dr Bren Neale (principal investigator), Dr Jennifer Flowerdew (Research Fellow) and Dr Amanda Wade. Visit www. leeds.ac.uk/family for the Final Report on this research grant.

4 For example, Mann argues '. . . life stories elicited through interview methods are perhaps affected by the 'audience' even more acutely than either autobiographies or group work.... It is not only power issues ... it is also the agenda that the interviewer pursues, and the means that are used to pursue that agenda within the relational dynamic of the interview'. (1998: 92)

5 As part of the interview we asked the children and young people to 'give advice' to a hypothetical couple who were thinking of separating and who had children. Of the 60 children only 2 said that they should not separate, but the majority offered advice on how the parents should manage the process based on their own experiences from which they were able to generalise.

\section{References}

Amato, P.R. and Booth, A., (1997), A Generation at Risk: Growing Up in an Era of Family Upheaval, Cambridge, MA: Harvard University Press.

Brannen, J., Heptinstall, E. and Bhopal, K., (2000), Connecting Children: Care and Family Life in Later Childhood, London: Routledge Falmer.

Bruner, J., (1987), 'Life as Narrative', Social Research vol 54: 11-32.

Butler, I., Scanlan, L., Robinson, M., Douglas, G. and Murch, M., (2003), Divorcing Children, London: Jessica Kingsley Publishers.

Cockett, M. and Tripp, J., (1994), The Exeter Family Study, Exeter: Exeter University Press.

Day Sclater, S., (1999), Divorce: A Psychosocial Study, Aldershot: Ashgate.

Duncombe, J. and Marsden, D., (2003), “"The Never-ending Story”: Children's Gaze and the Unresolved Narrative of Their Parents' Divorce', in Allan G. and Jones G. (eds), Social Relations and the Life Course, Basingstoke: Palgrave Macmillan.

Dunn, J., (2003), 'Contact and Children's Perspectives on Parental Relationships', in Bainham, A., Lindley, B., Richards M. and Trinder L. (eds), Children and their Families, Oxford: Hart Publishing.

Flowerdew, J. and Neale, B., (2003), 'Trying to stay apace: children with multiple challenges in their post-divorce family lives', Childhood: a global journal of child research, Vol 10 (2): $147-162$.

Furedi, F., (2004), Therapy Culture, London: Routledge.

Gergen, K.J. and Davis, K.E., (eds), (1985), The Social Construction of the Person, New York: Springer Verlag.

James, Adrian L. and James, Allison, (1999), 'Pump up the volume: Listening to children in separation and divorce', Childhood, 6: 189-206.

Mann, C., (1998), 'Family Fables' in Narrative and Genre (eds) M. Chamberlain and P. Thompson, London: Routledge 81-98.

Mason, J., (2004), 'Personal narratives, relational selves: residential histories in the living and telling', The Sociological Review, Vol 52(2): 162-179.

Mayall, B., (2003), Towards a Sociology for Childhood, Buckingham: Open University Press.

Maclean, M., (1991), Surviving Divorce: Women's Resources after Separation, London: Macmillan.

Morrow, V., (1998), Understanding Families: Children's Perspectives, London: National Children's Bureau. 
Morrow, V., (1999), “"We are People Too”: Children's and Young People's Perspectives on Children's rights and Decision Making in England', International Journal of Children's Rights, 7: 149-170.

Moxnes, K., (2003), 'Risk factors in divorce: perceptions by the children involved', in Childhood Vol 10 (2): 131-146.

Parkinson, P., Cashmore, J. and Single, J., (2005), 'Adolescents' Views on the Fairness of Parenting and Financial Arrangements After Separation', Family Court Review, 43 (3): 429-444.

Rose, N., (1996), Inventing Our Selves, Cambridge: Cambridge University Press.

Sayer, A., (2005), The Moral Significance of Class, Cambridge: Cambridge University Press.

Sheehan, G., Darlington, Y., Noller, P. and Feeney, J., (2004), 'Children's Perceptions of their Sibling Retationships during Parental Separation and Divorce', Journal of Divorce \& Remarriage, Vol 41 (1/2): 69-94.

Smart, C., Neale, B. and Wade, A., (2001), The Changing Experience of Childhood: Families and Divorce, Cambridge: Polity.

Stacey, J., (1996), In the name of the family, Boston: Beacon Press.

Stanton Rodgers R. and W., (1992), Stories of Childhood: Shifting Agendas of Child Concern, London: Harvester Wheatsheaf.

Thomson, R., Bell, R., Holland, J., Henderson, S., McGrellis, S. and Sharpe, S., (2002), 'Critical Moments: Choice, Change and Opportunity in Young People's Narratives of Transition' Sociology Vol 6 (2): 335-354. 